\title{
Smart Home Information Management System for Energy-Efficient Networks
}

\author{
Margherita Peruzzini, Michele Germani, Alessandra Papetti, and Andrea Capitanelli \\ Università Politecnica delle Marche \\ via Brecce Bianche 12, 60131 Ancona (AN), Italy \\ \{m.peruzzini,m.germani, e.marilungo\} @univpm.it
}

\begin{abstract}
Energy efficiency of smart home systems imposes the intelligent management of a huge quantity of data and the collaboration between multiple stakeholders. Indeed, thanks to recent developments in ICT (Information and Communication Technologies) and IoT (Internet of Things), it is possible to achieve higher performances and offer new energy-control services. However, data must be not only retrieved but also translated into significant information and related to interoperable tasks. This paper focuses on smart home energy control and defines a methodology to improve smart home information management in order to create an extended energy-efficient network comprehending the distributed manufacturing enterprise as well as the energy utility and the consumers. The case study focuses on a sub-set of interoperable smart devices and shows how to apply the proposed information management model to make an extended virtual enterprise provide energy-control services.
\end{abstract}

Keywords: Energy-efficient networks, Interoperable smart home systems (SHS), Internet of Things (IoT), Virtual Enterprise (VE), Energy-control services.

\section{Introduction}

The growing attention to sustainability and the capabilities of recent technologies suggest creating intelligent networks to realize a more efficient use of the energy resources. Such an idea is particularly interesting if applied to smart homes due to the high environmental impact of the residential sector (about $20 \%$ of total consumption) and the direct involvement of the users and influence on their everyday life to realize energy efficiency. Indeed, a smart home system (SHS) has heterogeneous elements that need to perform joint execution of tasks in an efficient manner to be really interoperable. Nowadays, data aggregation and sharing within the networks can be guaranteed by modern Internet of Things (IoT) approaches and supported by available Information and Communication Technologies (ICT) tools. At the same time, networks are evolving from the traditional concept of distributed enterprise as an aggregation of manufacturing companies and their supply-chains [1] to a new concept of Virtual Enterprise (VE) based on open service ecosystems [2]: a distributed virtual network made up of devices, manufacturers, service companies, public entities, until 
customers and their homes. The high-level objective is creating a continuous flow of information within the VE that can be used to support real-time decisions, optimize the use of resources and increase safety and quality of life.

In this context, information management and interoperability are fundamental to achieve efficient solutions. Indeed, the rising intelligence of smart devices makes a large amount of data available, but their complexity hinders classification, transmission and interpretation of essential data. Both aspects may drastically reduce the potential benefits and limit the diffusion of smart home energy management [3]. As a consequence, devices' interoperability in smart home is still an open issue [4].

In this context, the paper proposes a structured methodology to properly classify significant information and intelligently manage the smart device information network according to the devices' interoperability potentials and the users' needs. The main scope is to make home devices really interoperable and provide energy-efficient services by involving all the network partners, which include also the final users. The paper considers the most popular home devices and proposes an information management model to be implemented by a knowledge-based tool. The case study shows how to use the proposed methodology in practice. In particular, it is adopted to investigate and manage a smart home network comprehending a set of devices and a set of actors to create energy-control services.

\section{Information Management for Smart Home Interoperability}

The smart home is a special place where all the sub-systems are interconnected allowing the users to save energy, to reduce operating costs and to improve safety, comfort and multimedia services [5]. It implies creating a distributed system with many entities working together about the home dwellers and managing the interrelations between different sub-systems (i.e. home automation, digital entertainment, assistive computing, healthcare, surveillance, energy management).

In recent years the attention is mainly focused on technological integration and sub-systems communication, that are based on device connectivity and home area network (HAN) [6]. A considerable amount of new solutions for smart home automation have been recently developed, but each of them generally has a different communication protocol and requires a specific architecture. There are open or proprietary systems: the former has public operating specifications and proposes a standard communication protocol that can be used by companies to develop compatible devices (e.g. Konnex, Lonworks, Zigbee); the latter are produced by a single company or consortium for specific home automation systems and the technical information are usually reserved (e.g. SCS by Bticino and Legrand, By-Me by Vimar, C-BUS by Schneider Electric). In both cases, the definition of standards and common rules almost within a certain VE are fundamental to make devices interoperable and integrate products from different manufacturers [7]. However the core difficulty is achieving interoperability inside the SHS that means among the home sub-systems [7], and within the VE that means among the involved partners, each of which has a specific roles). The connection between SHS and VE interoperability mainly consists of the ability to manage the home sub-systems in relations to the actors involved, which are internal (e.g. home dwellers) and external (manufacturing companies, 
maintenance service providers, energy utilities, etc.). The issue of interoperability is particular challenging due to the huge amount of data to manage, the level of complexity of the devices' integration and the different roles of the partners involved. As a consequence, even if the idea of smart appliances connected within a home network is not new, efficient smart home management has still numerous open issues.

In this context, the European Committee of Domestic Equipment Manufacturers (CECED) established a preliminary application profile for smart home to collect and transmit data. However, data are rarely converted into significant information and used for real time feedback. Recent studies proposed several system architectures for interoperability and energy management purposes [6,8], and several projects have been developed in different countries about these topics: Smart Energy 2.0 [9], Energy@ home [10], E-Energy [11], ADDRESS [12], REserviceS [13]. Nevertheless, they deepen specific issues like monitoring, analyzing and estimating energy consumption [14], or investigate particular device applications (e.g. energy management by smart grids). None of them defines an overall and unique standard data management tool for high-level purposes. Other projects focused on data elaboration and data mining to realize services for different purposes, such as supporting manufacturing enterprises cooperation like MSEE [15], creating personcentric immersive environments like SM4All [16], or proving support to elderly people disabilities like HOPE [17]. However none of them cares about devices' interoperability and rule definition for information exchange between multiple partners. Furthermore TAHI (The Application Home Initiative) is working specifically on interoperability issues for the home [18], but VE is not considered.

In conclusion, even if different levels of interoperability have been recently defined (i.e. basic connectivity, network, and syntactic one) [6] and some companies have recently faced devices' remote control e.g. on white goods [19,20], real interoperability in smart home is not implemented yet due to: devices' regulation constraints, safety regulation constraints, and lack of interoperable system architecture. Indeed, interoperability tasks should be independent from the architecture capabilities and the devices' specific HW and SW characteristics [21]. In this context, applying a structured methodology for benchmarking smart home technologies and defining a successful knowledge management for smart home and connected VE is the starting point. The validity of such an approach has been demonstrated by past experiences in collaborative product design [22,23].

\section{The Methodology for Smart Home Energy Management}

The research presents a method to classify information for smart home energy management and define an intelligence-based model to manage interoperability and energy-efficiency in the VE. The approach can be synthetized in four steps:

1. Classification of smart home devices into homogenous classes (Tab.1): it considers the most popular devices in smart homes and catalogues them for typology, input and output data, and interaction modalities;

2. Identification of a set of significant information categories (Tab.2): it considers all the information to be managed in the smart homes for energy-control services; 
Table 1. Information model device classes

\begin{tabular}{l|l}
\hline Device class & Description \\
\hline $\begin{array}{l}\text { Household } \\
\text { Appliances (HA) }\end{array}$ & $\begin{array}{l}\text { It includes different classes of devices such as refrigerator and freezer, oven, hob, hood, } \\
\text { washer, dryer, and dishwasher, which are enhanced by a microcontroller to manage } \\
\text { automatic operation mode and a communication node to make them connected (e.g. Ultra- } \\
\text { Low cost Power-line (ULP)) }\end{array}$ \\
\hline Meters (M) & $\begin{array}{l}\text { It includes electricity, gas and water meters, whose data are communicated through the } \\
\text { home network and/or the smart grid in real time and can be remotely controlled. It can } \\
\text { include also control and safety systems (e.g. electrical safety, gas leaks, water leaks) }\end{array}$ \\
\hline $\begin{array}{l}\text { Environmental } \\
\text { Control (EC) }\end{array}$ & $\begin{array}{l}\text { It comprehends common classes of components such as lighting, doors, windows, alarm } \\
\text { system and sensors, window curtains and shutters, which can be grouped because they can } \\
\text { be controlled by similar functions (e.g. turn on/off, intensity regulation, opening/closing } \\
\text { control) }\end{array}$ \\
\hline $\begin{array}{l}\text { DHW and } \\
\text { HVAC (HW) }\end{array}$ & $\begin{array}{l}\text { It includes Domestic Hot Water devices (DHW), Heating, Ventilation and Air Conditioning } \\
\text { devices (HVAC), and all the devices and sensors related to their functioning (e.g. sensors of } \\
\text { indoor/outdoor temperature, humidity sensors) }\end{array}$ \\
\hline Consumer & $\begin{array}{l}\text { It includes a wide range of devices from entertainment (e.g. TV, game console, audio } \\
\text { equipment and players) and small household appliances (e.g. coffee makers, electronic } \\
\text { cutters or graters, toasters), which are characterized by constant and low energy } \\
\text { consumption, and off/on switching }\end{array}$ \\
\hline
\end{tabular}

Table 2. Information categories

\begin{tabular}{l|l}
\hline Information cat. & Description \\
\hline $\begin{array}{l}\text { Continuous } \\
\text { Monitoring (CM) }\end{array}$ & $\begin{array}{l}\text { It includes consumption information that is continuously monitored when the devices are } \\
\text { turned on (e.g. energy, water), which can be used to provide a feedback to users and VE } \\
\text { companies }\end{array}$ \\
\hline $\begin{array}{l}\text { User Interaction } \\
\text { (UI) }\end{array}$ & $\begin{array}{l}\text { It refers to all the information regarding the user-product interaction and characterizing the } \\
\text { users behaviors (e.g. selected options, duration of use, time of use, frequency). Such data are } \\
\text { used for statistic analysis and user behaviors investigation }\end{array}$ \\
\hline $\begin{array}{l}\text { Control } \\
\text { Parameters (CP) }\end{array}$ & $\begin{array}{l}\text { It considers the functional parameters of the home devices, which are continuously analyzed } \\
\text { and compared with target parameters. Such data are used to predict problems, detect } \\
\text { conditions, and supervise device functionality and user security }\end{array}$ \\
\hline $\begin{array}{l}\text { State Parameters } \\
\text { (SP) }\end{array}$ & $\begin{array}{l}\text { It refers to all information regarding the status of home devices, which is used to monitor a } \\
\text { particular scenario or to carry out device remote control }\end{array}$ \\
\hline $\begin{array}{l}\text { External data } \\
\text { (EXT) }\end{array}$ & $\begin{array}{l}\text { It refers to data generated by external entities (e.g. building typology, occupants' } \\
\text { characteristics, economic indicators, fees of utilities, climatic conditions) and device } \\
\text { reference information (e.g. datasheets, standard consumptions, etc.), contributing to define } \\
\text { the analyzed scenario }\end{array}$ \\
\hline $\begin{array}{l}\text { Derived data } \\
\text { (DER) }\end{array}$ & $\begin{array}{l}\text { It refers to data derived from post-processing elaboration and statistics analysis, which can } \\
\text { be used for realizing specific service functionalities (e.g. average time of use, average } \\
\text { expenditure over the time, use frequency) }\end{array}$ \\
\hline
\end{tabular}

3. Definition of an information management model (Fig.1): it correlates the information categories, the device functionalities, the input/output data and the VE actors for achieving smart home interoperability. For each device class, the information to be managed is identified. Also external and derived data are considered. At the same time, system actions are defined according to GET purpose (read and obtain information) and EXECUTE purpose (react and execute some commands). Also the data visualization for the different interfaces is defined. Finally, it allows defining the basic connectivity and network interoperability technologies to support the SHS design;

4. Definition of syntactic rules to create services: it provides a set of algorithms and interoperability rules to perform actions for energy-control services with reference to the VE actors (i.e. customers, energy utility, company depts.). 
The smart home model proposed could be implemented exploiting the following technologies: power line standards for basic connectivity (e.g. X10, HomePlug), wired and wireless communication standards (e.g. TCP, Ethernet, USB, HomePNA as wired, ZigBee, Wi-Fi, Bluetooth as wireless) for network interoperability. Data are concentrated into a local gateway that bridges the HAN and the Internet [24].

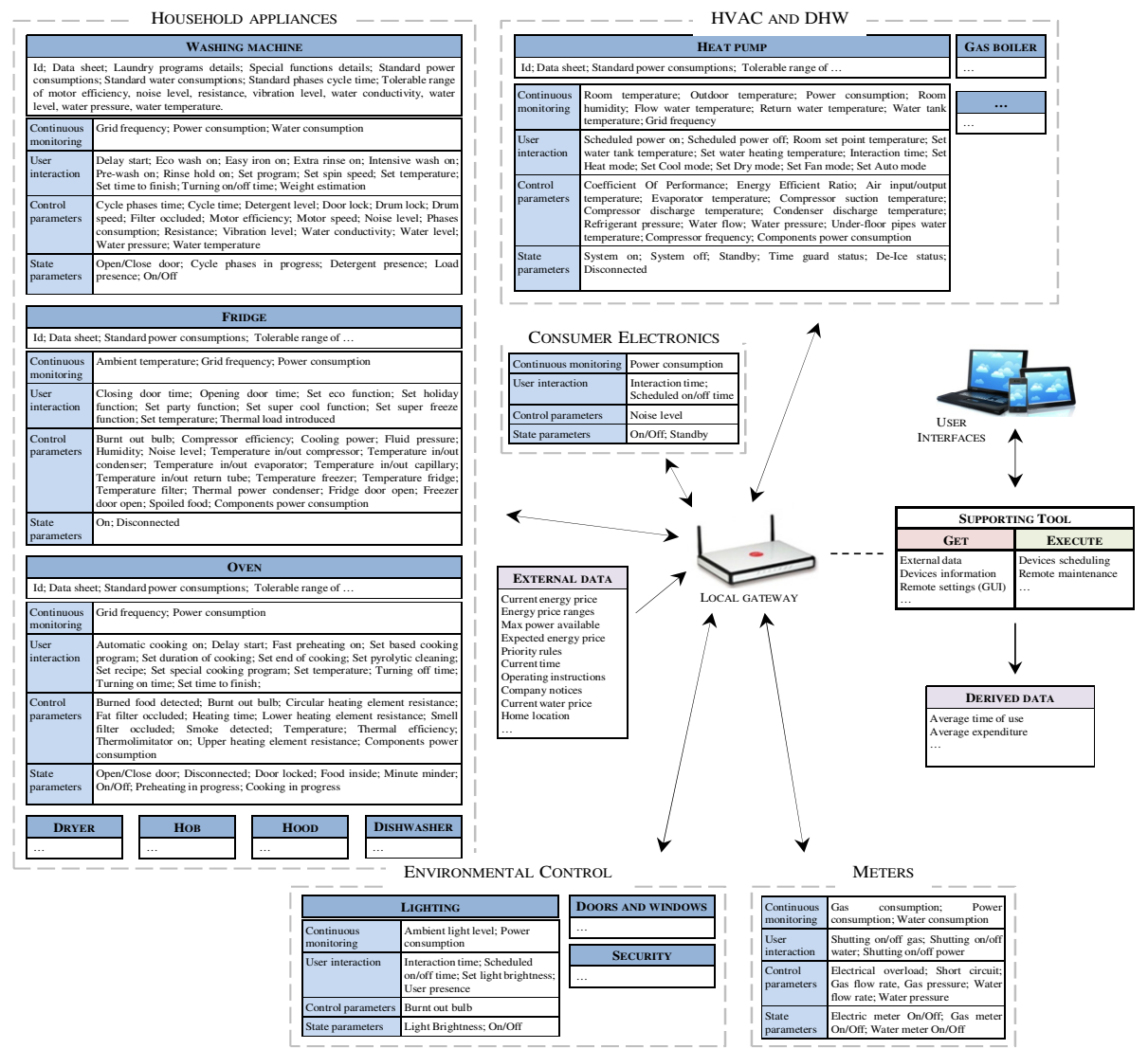

Fig. 1. Information management model for the smart home

The definition of a general model is the key point to realize intelligent-based services able to exploit device interoperability. Such a methodology supports the creation of a virtual smart home environment where systems data are managed and VE partners interoperate. It brings to the creation of a collaborative system for supporting dynamic virtual enterprise, similarly to recent experiences in product collaborative design [25].

\section{The Case Study}

The proposed methodology is adopted to create an interoperable smart home network where all devices as well as actors involved cooperate to realize services. In particular, 
the case study focuses on energy saving and considers a set of appliances representing the most energy consuming and most popular devices in dwellings: heat pump (HP) for HW class; washing machine, oven, and fridge for HA class; lighting (L) for EC class; and a set of generic items for $\mathrm{CE}$ and $\mathrm{M}$ classes. Indeed, $\mathrm{CE}$ items can be generalized by considering a sub-set of information provided by a generic smart plug (e.g. energy consumption, interaction time and device status); similarly, $\mathrm{M}$ items can be represented by consumption and control parameters (e.g. short circuit, gas leaks, water leaks). The case study considers hypothetical system architecture as proposed in section 3: it is made up of a set of smart devices and smart plugs, a Zigbee communication node, a local gateway to collect all data and make them available to a central management system (i.e. Energy Manager), and a set of user interfaces (i.e. web or mobile apps). The Energy Manager can apply specific algorithms to properly manage data and provide commands. Interaction between the devices and the management tool is ensured by a dedicated application. Data can be accessed by dedicated interfaces, which consider the needs of the ecosystem actors: appliances producers (e.g. marketing dept., R\&D, and service dept.), home automation supplier, energy utility, technical assistance companies, and the consumers. Two services are conceived and described below. Both services exploit the network interoperability to overcome the main limits of the existing systems, which usually provide just energy consumption visualization and regulation. The proposed scenarios offer advantages to all the ecosystem actors according to a "win-win" strategy. Obviously, private information and personal data can be properly treated to assure users' data security and protect private rights for the smart home dwellings.

\section{Service no.1: Smart Device Scheduling}

It offers an intelligent regulation of the devices' functioning to final users in order to save energy and reduce home consumptions. It indirectly allows also reducing the operational cost and improving the users' quality of life. The Energy Manager allows running specific algorithms for efficient device scheduling according to external parameters and user preferences. Figure 2 presents the Out of home scenario that consists of four modes: I'm going out is automatically activated when the user goes out; I' $m$ out is activated during the absence to monitor the home devices according to the pre-defined preferences; I'm coming back is activated when the user comes back and uses internal and external data to enable the desired functions (e.g. turning on and preheating the oven according to the effective user's coming); finally I' $m$ here considers the user's setting preferred when he/she is at home. For each mode, the system defines a set of actions (EXECUTE) to achieve the expected results according to the information received and read $(G E T)$. The service offers standard control actions (e.g. switching off lighting and alarm system), energy overload management and devices scheduling (i.e. according to the energy cost and user preference in terms of priority, start or finish time), upgrading according to real time user's notifications (e.g. change of the expected finish time for the washing machine), and grid balancing (e.g. windows opening regulation according to the weather).

\section{Service no. 2: Recommendations for Optimal Use and Product Care}

It aims to assure correct product maintenance and support the users in taking care about their devices by remote assistance and personalized recommendations. It finally 
allows optimizing the devices' consumption and cost, and keeping the home safe. Such a service basically exploits CP data collected from the devices to automatically detect malfunctioning and run preventive or predictive actions. For instance, during washing machine operation "cycle phases time" and "consumptions" data can be transmitted to the technical assistance company or to the manufacturer to be analyzed.

\begin{tabular}{|c|c|c|c|c|c|c|}
\hline \multicolumn{3}{|c|}{ I'M GOING OUT } & & \multicolumn{3}{|c|}{ I'M OUT } \\
\hline FLOW & GET & EXECUTE & & FLOW & GET & EXECUTE \\
\hline \multirow[b]{2}{*}{$\mathrm{HA} \rightarrow \ldots \rightarrow \mathrm{SP} \rightarrow$} & \multirow[t]{2}{*}{$\begin{array}{l}\text { Return at home time; Set } \\
\text { time to finish; Anticipate } \\
\text { start; Scheduled start; } \\
\text { Close all windows on } \\
\text { All parameters }\end{array}$} & \multirow[t]{2}{*}{$\begin{array}{l}\text { Control if the state parameters are } \\
\text { comply with the conditions to } \\
\text { enable the remote control else } \\
\text { notice the user. Close windows if } \\
\text { the related function is on. }\end{array}$} & & \begin{tabular}{r|r|}
$\mathrm{GUI} \rightarrow$ \\
$\mathrm{EXT} \rightarrow$ \\
$\mathrm{HW} \rightarrow \mathrm{HP} \rightarrow \mathrm{CM}$ \\
\end{tabular} & $\begin{array}{l}\text { Automatic regulation on; } \\
\text { Max open time } \\
\text { Weather; Wind } \\
\text { Outdoor T }\end{array}$ & $\begin{array}{l}\text { Regulate the windows } \\
\text { opening/closing according to user } \\
\text { settings and external conditions. }\end{array}$ \\
\hline & & & & \multirow{2}{*}{ GUI $\rightarrow$} & \multirow{2}{*}{$\begin{array}{l}\text { User update about Return } \\
\text { at home time and others } \\
\text { settings }\end{array}$} & \multirow{2}{*}{$\begin{array}{l}\text { Upgrade the scheduling } \\
\text { according to the new settings. }\end{array}$} \\
\hline \multirow{2}{*}{$\begin{aligned} & \mathrm{EC} \rightarrow \mathrm{L} \rightarrow \mathrm{SP} \rightarrow \\
& \mathrm{CE} \rightarrow \mathrm{SP} \rightarrow \\
& \mathrm{HW} \rightarrow \mathrm{HP} \rightarrow \mathrm{CM} \rightarrow \\
&\end{aligned}$} & \multirow{2}{*}{$\begin{array}{l}\text { On/Off } \\
\text { On/Off } \\
\text { Rooms and outdoor T } \\
\end{array}$} & \multirow{2}{*}{$\begin{array}{l}\text { Activate alarm system; Switch } \\
\text { off lighting; Set Heating ECO } \\
\text { mode. }\end{array}$} & & & & \\
\hline & & & & & \multirow[b]{2}{*}{ - } & \multirow{2}{*}{$\begin{array}{l}\text { Turn on the specific device at the } \\
\text { scheduled time. }\end{array}$} \\
\hline \multirow{5}{*}{$\begin{aligned} \mathrm{M} & \rightarrow \mathrm{CM} \rightarrow \\
\mathrm{HA} \rightarrow \ldots & \rightarrow \mathrm{UI} \rightarrow\end{aligned}$} & \multirow{5}{*}{$\begin{array}{l}\text { Standard power } \\
\text { consumptions } \\
\text { Power consumption } \\
\text { Scheduled turning on; } \\
\text { Scheduled cycle duration; } \\
\text { Scheduled cycle/phases } \\
\text { consumptions } \\
\text { Current energy price; } \\
\text { Energy price ranges; Max } \\
\text { power available; Expected } \\
\text { energy price; Priority } \\
\text { rules; Current time }\end{array}$} & \multirow{5}{*}{$\begin{array}{l}\text { Schedule the devices start that } \\
\text { minimizes the energy expenditure } \\
\text { for the user according to the } \\
\text { priority rules, max power } \\
\text { available and the user needs. } \\
\end{array}$} & & \multirow{2}{*}{$\mathrm{M} \rightarrow \mathrm{CM} \rightarrow$} & & \\
\hline & & & & & Grid frequency & $\begin{array}{l}\text { Cycle management by means } \\
\text { DDC technology. }\end{array}$ \\
\hline & & & & \multicolumn{3}{|c|}{$\downarrow$} \\
\hline & & & & \multicolumn{3}{|c|}{ I'M COMING BACK } \\
\hline & & & & FLOW & GET & EXECUTE \\
\hline & & & \multirow{4}{*}{$\longleftarrow$} & \multirow[t]{3}{*}{$\mathrm{HW} \rightarrow \mathrm{HP} \rightarrow \mathrm{CM} \rightarrow$} & \multirow[t]{3}{*}{ Rooms and outdoor $\mathrm{T}$} & \multirow{3}{*}{$\begin{array}{l}\text { Turn on the devices that have an } \\
\text { anticipate start in respect to the } \\
\text { Return at home time. } \\
\text { Disable the heating ECO mode. }\end{array}$} \\
\hline \multicolumn{3}{|c|}{ I'M HERE } & & & & \\
\hline FLOW & GET & EXECUTE & & & & \\
\hline GUI $\rightarrow$ & Welcome on & Deactivate alarm system. & & & & Switch on "welcome" lighting. \\
\hline
\end{tabular}

Fig. 2. Tool rationale of the "Out of home" scenario

Post-processing allows detecting whether the monitored parameters (e.g. motor speed, resistance) move away the standard or exceed the expected thresholds. Furthermore, analyzing the correlation between CP, SP, CM and UI data allows capturing also hidden malfunctioning (e.g. if the temperature in the oven is different from the set temperature, the system controls the program set and the resistance value and finally provides an alert). The user is noticed by messages about devices' troubles, necessary repairing actions or scheduled interventions.

\section{Conclusions}

The paper proposes a methodology to improve smart home information management by promoting device interoperability and network collaboration for energy efficiency. It aims to overcome the main issues of existing SHS by mapping the devices' functions and data, correlating the devices' functions with the smart home actions, and defining what information to send/receive to propose energy-control services. The case study shows how the proposed method can be adopted to realize energy saving services in smart homes by involving different network actors. The proposed examples highlight the achievable advantages: the customers have a continuous feedback on their product functioning, save energy and cost, and benefit from the reduction of failure rates and downtime; the appliances producers monitor their product by receiving useful information and can provide efficient and immediate assistance (Technical service Dept.), can highlight the most critical aspects to define design improvements (R\&D Dept.), and can identify the users' behaviors to conceive new marketing proposal (Marketing Dept.); technical assistance companies and home automation suppliers can 
cooperate with the manufacturer to offer additional or customized maintenance services; utilities can create customized services and collaborate with the other ecosystem actors to create new business opportunities. Future works will be oriented to the development of a prototypal system to test services with the involvement of a real VE, and the definition of a proper data security protocol to protect the personal rights and privacy issues of the smart home dwellings.

\section{References}

1. Byrne, J.A., Brandt, R., Port, O.: The virtual corporation. The company of the future will be ultimate in adaptability. Business Week 36, 36-40 (1993)

2. Chesbrough, H.: Open Innovation. Harvard Business School Press, Boston (2003)

3. Kim, S.L., Hwang, J.: Real-time Energy Monitoring and Controlling System based on ZigBee Sensor Networks. Proc. Computer Science 5, 794-797 (2011)

4. Chen, C.Y., Tsou, Y.P., Liao, S.C., Lin, C.T.: Implementing the Design of Smart Home and Achieving Energy Conservation. In: 7th IEEE Int. Conf. Industrial Informatics, pp. 273-276 (2009)

5. Wong, J.K.W., Li, H., Wang, S.W.: Intelligent building research: A review. Automation in Construction 14, 143-159 (2005)

6. Perumal, T., Ramli, A.R., Leong, C.Y., Samsudin, K., Mansor, S.: Interoperability Among Heterogeneous Systems in Smart Home Environment. Atlantis Ambient and Pervasive Intelligence 2, 141-157 (2010)

7. Kailas, A., Cecchi, V., Mukherjee, A.: A Survey of Communications and Networking Technologies for Energy Management in Buildings and Home Automation. Journal of Computer Networks and Communications, Article ID 932181 (2012)

8. Alam, M.R., Reaz, M.B.I., Ali, M.A.M.: A Review of Smart Homes-Past, Present, and Future. IEEE Trans. on Systems, Man, and Cybernetics-Part C 42, 1190-1203 (2012)

9. Smart Energy, http: //www. zigbee.org/SmartEnergy

10. Energy@ Home,http://www.energy-home.it

11. E-energy, http://www.e-energy.de

12. ADDRESS, http://www . addressfp7.org

13. REserviceS, http: //www.reservices-project.eu

14. Shin, J., Hwang, J.: Intelligent energy information service based on a multi-home environment. Proc. Computer Science 10, 197-204 (2012)

15. MSEE Manufacturing Service Ecosystem, http://www.msee-ip.eu

16. Sm4ALL, Smart Homes for All, http://www.sm4all-project.eu

17. HOPE, Smart Home for Elferly People, http : / /www. hope-project. eu

18. TAHI, The Interoperable Services for Smart Home, http: / / www. theapplicationhome.com

19. Bansal, P., Vineyard, E., Abdelaziz, O.: Advances in household appliances - A review. Applied Thermal Engineering 31, 3748-3760 (2011)

20. Ricci, A., Aisa, V., Cascio, V., Matrella, G., Ciampolini, P.: Connecting electrical appliances to a Home Network using low-cost Power-Line Communication. In: Proc. Int. Symposium on Power Line Communications and Its Applications, pp. 300-304 (2005)

21. Bonino, D., Corno, F., De Russis, L.: Home energy consumption feedback: A user survey. Energy and Buildings 47, 383-393 (2012) 
22. Germani, M., Mengoni, M., Peruzzini, M.: A benchmarking method to investigate codesign virtual environments for enhancing industrial collaboration. In: Proc. ASME World Conference on Innovative VR 2010 (WINVR), Ames, IOWA (USA), May 12-14 (2010)

23. Mengoni, M., Germani, M., Peruzzini, M., Mandolini, M.: A novel knowledge-based approach to support virtual teamwork in collaborative design. In: Virtual Engineering, Int. Conf. Tools \& Methods of Competitive Engineering, Ancona, Italy, April 12-16, vol. 1, pp. 461-474 (2010)

24. Cheng, S.T., Wang, C.H., Horng, G.J.: OSGi-based smart home architecture for heterogeneous network. Expert Systems with Applications 39, 12418-12429 (2012)

25. Germani, M., Mandolini, M., Mengoni, M., Peruzzini, M.: Collaborative design system for supporting dynamic virtual enterprises. In: Camarinha-Matos, L.M., Boucher, X., Afsarmanesh, H. (eds.) PRO-VE 2010. IFIP AICT, vol. 336, pp. 577-584. Springer, Heidelberg (2010) 